\title{
浅析\#3 炉汽包水位波动大的原因
}

高波

邹平县宏旭热电有限公司

DOI:10.32629/hwr.v3i3.1986

[摘 要] 汽包水位是锅炉正常运行中最主要的监视参数之一, 锅炉满水时蒸汽大量带水, 会引起蒸汽管道和汽轮机产生严重 的水冲击,造成重大设备损坏。水位过低,会引起水循环的破坏,使水冷壁管超温过热,严重缺水时,还可能造成更严重的设备损 坏事故。因此,加强对汽包水位的监视和调整至关重要。本文结合某公司\#3 炉在机组检修启动后汽包水位波动大情况,通过给 水控制系统及燃烧等方面分析, 得出了一套切实可行的办法, 使水位调整难题得到初步解决, 现对汽包水位治理情况简述如下。 [关键词] 锅炉; 汽包水位; 给水自动

\section{引言}

某公司\#3 机组容量为 330MW, 锅炉为无锡锅炉厂生产的 UG-1217/18. 4-M 型亚临界、中间再热、自然循环汽包炉, 设 计煤种为贫煤。 24 只煤粉燃烧器、三层 12 只机械雾化轻柴 油燃烧器以及一层 4 只微油燃烧器, 四角布置, 切圆燃烧; 制 粉系统为三台正压冷一次风直吹式钢球磨煤机, 配两台变频 离心一次风机。给水系统配有两台汽动给水泵和一台 $50 \% \mathrm{MCR}$ 电动给水洜。DCS 系统为和利时公司 MACSV5.2.4 系统。

2018 年 03 月 19 日\# 3 机组检修启动后, 相同工况下汽包 水位波动较之前明显增大, 汽包水位波动经常超过 $\pm 100 \mathrm{~mm}$, 给机组安全运行带来较大威胁。 $\# 3$ 炉汽包水位难以调整, 主 要表现在以下方面: (1)\#3 炉 3-1、3-2、3-3 汽包平衡容器 水位偏差大, 正常情况下偏差 $50 \mathrm{~mm}$ 以上, 水位波动大时 $3-1$ 、 3-3 汽包水位偏差能到 200mm 左右。(2)给水自动调整频繁出 现振荡, 需经常人为修正水位设定值以恢复汽水平衡关系。 (3)受燃烧影响大, 在炉膛温度出现偏差或投退粉嘴时汽包水 位出现明显偏差并波动大情况。

\section{1 影响汽包水位波动大的原因分析}

1.1 给水自动影响

汽包给水自动正常取自汽包平衡容器三取中, 此次机组 启动前后服务器未进行下装, 给水自动调节 PID 未做修改。 查阅汽包平衡容器水位历史曲线, 发现 3-1、3-2、3-3 水位 曲线经常出现变化速率不一致而相交现象。因运行中汽包水 位跟踪值为三个平衡容器水位中值, 当某个非中值水位出现 波动, 变化曲线较中值曲线反向交叉时, 给水自动跟踪值会 重新选择, 造成给水自动跟踪值波动大, 影响给水自动波动。 如果遇有燃烧变化等因素影响汽包水位变化时, 人员不及时 干预给水自动设定值, 会造成给水洜调节幅度与汽包水位变 动频繁, 引起给水自动调节振荡。

\section{2 锅炉燃烧影响}

燃烧工况的改变对水位的影响也很大。在外界负荷及给 水量不变的情况下, 当燃料量突然增加, 水位暂时升高而后 下降; 燃料突减, 水位暂时降低而后升高, 这是由于燃烧工况 的改变使炉内放热量改变, 而引起工质状态发生变化的缘
故。当燃烧强化时, 炉水吸热量增加, 汽泡增多, 体积膨胀, 而使水位暂时升高。由于产生的蒸汽量不断增加, 使汽压上 升, 饱和温度也相应地提高了, 炉水中汽泡数量又随之减少, 水位又下降。因此水位波动的大小, 取决于燃烧工况改变的 强烈程度以及运行调节的及时性。

\section{3 表计指示不准影响}

对汽包平衡容器水位保温排查: 就地测平衡容器冷凝罐 及水侧管路温度分别为 $3-1: 290 / 170{ }^{\circ} \mathrm{C}, 3-2: 278 / 176$ ${ }^{\circ} \mathrm{C}, 3-3: 288 / 172^{\circ} \mathrm{C}$, 温度差别不大, 说明保温方面正常, 不会 引起测量偏差。3-1、3-2 平衡容器水位计处于汽包西侧, 3-3 汽包平衡容器水位计处于汽包东侧, 3-1与 3-2 处于同侧, 理 应变化方向及幅度相差不大, 但实际三个平衡容器水位中属 3-1 波动幅度最大。04 月 27 日, 热工将 3-1 平衡容器水位变 送器与 3-1 二级减温水流量变送器进行对调, 对调后汽包水 位变化无明显减缓趋势, 故排除汽包水位变送器故障导致汽 包水位波动。

\section{4 汽包内部装置异常影响}

锅炉汽包内设置旋流式分离器, 直径为 $292 \mathrm{~mm}$ 。汽水混 合物在其中旋转, 为平衡汽包水位, 采取旋流式分离器对称 布置, 当出现某一个旋流式分离器故障时会出现汽包水位不 平衡, 汽包水位波动大的情况。但是后来通过试验调整\#3 炉汽 包水位趋于稳定, 故排除汽包内部装置异常影响水位的因素。

\section{5 阀门内漏影响}

与锅炉水室相连接的有汽包事故放水电动门及锅炉定 排、下降管排污电动门, 由于锅炉水室压力高达 $18.5 \mathrm{Mpa}$ 左 右, 当与水室相连的阀门出现内漏时, 泄漏量相当的, 对汽包 水位影响很大, 特别是在锅炉定期排污时, 对汽包水位影响 较大。锅炉正常运行中, 定排手动门、电动门全开状态下排 污量在 $200 \mathrm{t} / \mathrm{h}$ 左右, 若阀门存在内漏情况, 对汽包水位影响 较大。但正常运行中, 汽包事故放水、各排污手动门、电动 门均处于关闭状态, 且通过阀门测温未发现内漏严重情况, 故排除阀门内漏对汽包水位的影响。

1.6 炉水品质影响

当给水处理不当以及锅炉排污不及时等造成炉水品质 
不合格而长期运行时, 使炉水含盐量过大, 不但会造成蒸汽的 污染, 而且会在水冷壁受热面上结垢, 甚至会腐蚀受热面, 影 响传热效果, 进而影响循环水速, 使汽包各分离器进水量发生 改变, 影响汽包水位。同时由于炉水中的油脂、悬浮物或含盐 浓度过高, 汽泡的表面含有杂质而不易破裂, 在汽包水面上产 生大量泡沫, 使汽包水位急剧升高并产生强烈波动现象。

\section{7 减温水调整影响}

汽包水位反应的是给水、蒸汽平衡关系, 给水自动调整 时减温水流量未计入给水流量, 若减温水调整幅度过大, 会 造成汽水平衡关系破坏, 造成汽包水位波动。

1.8 汽包加药、锅炉连排影响

分别试验暂停锅炉汽包加药、锅炉连续排污, 检查这两 方面对汽包水位的影响。经过试验, 水位变化幅度无明显变 化。因此可排除加药、连排的影响。

\section{2 燃烧方面检查及分析}

$2.1 \# 3$ 炉自 2017 年共计检修三次, 分别为 2017 年 03 月份水冷壁爆破检修、2017 年 11 月份状态停运检修, 2018 年 02 月份水冷壁爆破检修。期间两次故障停运, 锅炉均因汽 包无法补水, 降压速度过快原因, 造成汽包上下壁温差最高 达 $84^{\circ} \mathrm{C}$ 。因锅炉受热面故障后造成汽包内工质流向突变, 可 能会造成汽包内部汽水分离器等位置变化, 导致汽包内工质 波动情况。

2.2 上次机组停运期间发现\#3 炉水冷壁管高温腐蚀严 重, 但受机组检修进度影响, 只进了泄漏水冷壁的更换, 未对 高温腐蚀部位进行更换及喷涂, 水冷壁受热面局部腐蚀、结 垢可能会导致两侧水冷壁吸热量偏差大, 产汽量、循环水速 不同从而进入汽包时对水位冲击不同, 引起汽包两侧水位偏 差及水位波动幅度大。

\section{3 处理措施}

通过这几次试验, 虽未能从根本上解决\#3 炉汽包水位波 动大的问题, 但通过试验及分析历史曲线总结出了现行条件 下保证锅炉水位稳定的暂行方法: (1)运行中注意监视给水流 量、蒸汽流量差值, 加强汽包水位中值监视, 发现中值变换时 及时按变换值修正水位设定值, 保持汽水平衡关系不被破 坏。当出现水位偏差大屏蔽, 给水自动跟踪值变换为平均值
时, 若变换值超过 $50 \mathrm{~mm}$ 时, 立即解除给水自动, 手动稳定给 水流量, 待水位跟踪值变回中值且稳定后再重新投入给水自 动。(2)\#3 炉 3-1 水位变化速率较 3-2、3-3 水位明显较大, 运行中保持给水自动跟踪 3-2、3-3 水位, 若出现跟踪 3-1 水 位时, 及时联系热工补偿水位, 使跟踪值变回 3-2 或 3-3 水 位。但补偿水位时一定要注意不可与就地对应侧的双色水位 计或磁翻板水位计实际水位偏差过大。同时, 水位补偿时禁 止对三个水位进行补偿, 最好一次只补偿一个, 记录好补偿 量, 以便后续再次补偿时有所依据。(3)运行人员提高对环境 温度变化敏感度, 当出现大幅降温、大风、下雨天气时, 及时 检查汽包水位波动情况, 加强水位监视调整。日常巡检汽包 房时注意关闭好各部门窗, 防止汽包两侧环境温度不同影响 水位测量误差。(4)锅炉燃烧调整及工况变化时加强水位监视, 及时增设专人监视汽包水位, 防止出现水位波动调整不及时 引发锅炉水位事故。(5)汽包水位出现波动期间, 机组禁止进 行影响汽包水位操作, 待水位稳定后再进行。(6)做好水位计 校对工作, 发现两侧汽包水位偏差及平衡容器/就地水位计 偏差时, 及时汇报, 联系热工检查, 同时做好燃烧分析, 消除 不正常燃烧方式, 保证锅炉燃烧稳定, 避免燃烧工况变化造 成汽包水位波动。(7)加强主再温度监视, 勤调、细调, 禁止大 幅调整减温水, 防止汽水平衡瞬间波动引起汽包水位波动。

\section{4 结束语}

\#3 炉汽包水位问题是现今影响机组安全稳定运行的主 要因素, 依据本文所述措施执行, 目前\#3 炉汽包水位调整收 效较好, 未出现过水位大幅波动。但影响平衡容器水位偏差 大的问题仍需进一步分析, 找出根本原因进行治理, 保证锅 炉机组安全稳定运行。

\section{[参考文献]}

[1]沈赫男,周宏斌,牛树森.汽包水位波动原因分析[J]. 自动化应用,2018,(06): 114-115.

[2]刘建华,李哲姝.温度波动下的锅炉汽包水位模糊控 制方法[J].自动化仪表, 2016,37(05):87-89.

[3]冯忠宝,刘一凡,司瑞才, 等.350MW 机组汽包水位波动 大的分析及处理[J].吉林电力, 2018,46(03):50-53. 